\title{
Application and Development of Multimedia Technology in Dance in China
}

\author{
Yanling Sun ${ }^{1, *}$
}

\author{
${ }^{1}$ The University of Edinburgh \\ *Yanling Sun. Email: yanlingsun313@126.com
}

\begin{abstract}
As the economy and technology continue to develop, technology, and multimedia are being used extensively in music, art, and dance. In particular, during the Covid-19 period, dance as an offline art was hit hard by isolation and social distance. Dancers and dance teachers have increased their internet, and digital media use to strengthen the links between dances. In addition, as digital media develops, the connection with dance will inevitably increase. Therefore, it is essential to analyse the application and development of multimedia technology in dance to take stock of and reflect on the current form of dance. Prospects and presuppositions are made in the form of dance.

The result showed that by analyzing the application of multimedia technology in dance, the method of using multimedia technology was explored in dance performance and dance education, including the possible application of videos and projections, virtual reality and interactive installation in dance performances and choreography. In dance education, video, online classes, and audio provided the developmental scope of dance teaching. This research summarizes and prospects the intersection of dance and multimedia technology disciplines, lists the standard choreography methods of multimedia technology and dance, and teaches models that provide valuable thinking about the future development of dance.
\end{abstract}

Keywords: multimedia technology, dance performance, dance education, dance form

\section{MULTIMEDIA TECHNOLOGY IN DANCE PERFORMANCE}

With the development of multimedia technology, multimedia is widely used in dance theatre and stage performances. In dance, video and projection, virtual reality and interactive installations combine multimedia and dance, thus enriching dance. Through video and projection, the atmosphere can be easily activated, and the dancer's expressiveness can be enhanced (Tardieu, 2010). With virtual reality, dance becomes immersive and creative (Chan et al, 2010). The application of interactive installations strengthens the connection between the audience and the dancers, turning dance into a more integrated art form (Leo, 2007). Multimedia technology is widely used in dance, bringing many possibilities for stage art, dance performance and choreography.

\subsection{Video and Projection}

Video and projection are often used in dance works. The use of multimedia in dance has evolved from simple video projection to the holographic projection epidemic today. For example, Chris Cross's work "Into the Light" used projection to combine the robotic arm's movements with those of the dancers. Pixel n'Pepper used the LED screen to show its shadow as a video dance. In addition, the use of video and projection in many dance pieces serves to heighten the atmosphere and enhance the expression of the dancers.

Video and projection can serve a specific role to render the atmosphere (Jola \& Grosbras, 2013). Because the digital image is a three-dimensional visual effect, it can present virtual objects, characters, and environments on display from multiple angles and linearly. Therefore, in virtual displays, light and electricity are used in modern art performances, which are more realistic and sensory oriented. With the addition of stereoscopic display technology, the $3 \mathrm{D}$ images presented to the audience are more realistic and give people a sense of immersion. At present, many photographic techniques and equipment are increasingly used in stage performances. For example, LED electronic display, screen projection, and other standard technologies have 
been widely used in dance theatres and dance works. In China, a typical example is the dance drama "Zhu Ziqing", which uses a large LED screen as a stage backdrop and projects corresponding images in conjunction with the dancers' movements to enhance the audience's sense of experience and dance performance atmosphere. More clearly, in the separate scene of this dance, the scene projected on the LED screen is a rainy environment, so it is suitable for the background of the story to enhance the atmosphere of the theatre.

In addition, the use of video and projection is conducive to improving the expressiveness of the dance (Tardieu, 2010). Nowadays, the development of technology has appeared in the use of various high-tech products in dance performances, presenting a refreshing effect on stage, which is in line with people's modern concept of aesthetics and cultural consumption, and the stage art and technology have become an inseparable part of the dance performance. For example, in work "BreakBlind" by the Beijing 9 Contemporary Dance Company, the dancers wear mobile phones on their faces, and the screens of the mobile phones are pre-recorded videos. This novel dance form also increases the audience's interest in watching. The video intervention transforms the dance from a single form to a rich experience, demonstrating the power of multimedia technology to enhance the spectacle of dance performance (Parrish, 2007).

\subsection{Virtual Reality}

Virtual Reality has evolved from its beginnings as a VR game to a creative tool combined with art. In dance, VR technology is also widely used in dance performances. For example, in Shanghai, China, the famous VR show is "VR_I". "VR_I" is an immersive virtual reality contemporary dance piece created by renowned Swiss choreographer Jill Jobin and top technical team Artanim. In this system, five people wearing VR devices need to experience it simultaneously to see each other's virtual images. In the VR system, there are endless deserts, cities, and mountains. The experiencers can turn into giants and dwarfs and dance with virtual dancers. This is a unique interactive experience for the audience that allows them to walk through real space, interact with the virtual dancers and ultimately achieve an excellent mood indistinguishable from reality. The system consists of 96 photogrammetric scanners. Before the performance begins, the system first scans the dancers' bodies and movement trajectories in 3D. The choreography team creates and films the animation using infrared cameras. During this process, the costume designer completes the design of the scanned images of the virtual dancers, the 3D artist is responsible for integrating the virtual environment, and the sound artist needs to set up the sound environment in the 3D engine. Then apply the captured motion capture data to the virtual body; the animation is further scanned and processed by the game engine (Unity 3D software) under the guidance of the choreographer. Finally, Artanim's technical team manages all the project data in their natural virtual 'Real Virtual' technology system. This shows that virtual reality can be applied to dance performances, making them creative and giving the audience an unforgettable experience and creativity.

VR has evolved to the point where it is now used as a training system and a staging art. VR use in the staging of dance performances can be more creative and immersive for the audience (Kyan et al., 2015). In short, VR technology is a product of rapid technological development. The combination of dance and virtual reality has many benefits, and this approach is highly feasible. In the future, there will be unlimited scope for the integration of VR technology with the dance profession (Chan, et al., 2010).

\subsection{Interactive Installation}

The concept of installation art is the direct use of the physical object of the objective world as an expression of artwork, in which the artist selectively assembles and collages to create a new work that relies on the creator's sense of reinvention of the finished product and the new aesthetic sensations that the recipient gives to the installation when viewing it (Leo, 2007). Nowadays, the interactive work of the computer provides more possibilities for artistic expression.

Interactive installations require the intervention of new media technologies. For instance, information is collected via tracking balls, joysticks, graphic input boards, sound input devices, infrared sensors, and video input devices, and then output via projection, split-screen, concave mirrors, sound output devices and video output devices. This is a new method to capture the dancer's dynamic route and image accurately. Thus, the interactive installation intervenes in the original threedimensional environment. It becomes the art of expressing four-dimensional space and time, which can be viewed and triggered through a specific information collection system to achieve artistic effects rather than the work itself. A noteworthy example is the interactive installation dance piece "Rainbow Dance" in China. The installation of this work is based on MSP, Processing, and visual image sensing devices to complete. In this process, the moving human body transmits the visual information to the computer through the impact capture device. The device is pre-programmed to reduce the image to digital and then completes the dot matrix image through digital processing calculation, output through the video projection device. In this work, the 3D image of the dancer dances with the dancer himself, completing the choreographer's expression of the content of the work. In this work, the choreographer aims to make the dancer talk with his soul. 
Dance has encountered exciting new frontiers of technology in the 21 st century. Interactive installations are one of the many multimedia technologies that have become popular for artistic expression in dance. It also brings fresh energy and outlook to the future development of dance forms.

Choreographers working through multimedia technologies can generate unexpected and fresh movement (Leo, 2007). They provide a rigorous intellectual, physical, and creative experience for the dancers involved and fostering new collaborative ventures around the world. Different countries and regions are now available to anyone with a mobile space and internet connection. This dynamic has the potential to become one of the newest and most engaging experiences for young choreographers, artists who are already addicted to their respective technical devices. Dancers can begin to negotiate and bridge the space between the embodied and the digital, opening up new and uncharted territories for the future of dance (Parrish, 2007).

\section{MULTIMEDIA TECHNOLOGY IN DANCE EDUCATION}

Video and online dance classes have collaboratively created a dance environment and offered dance opportunities across long distances via Multimedia technology over the last two years. During Covid-19, in particular, dance educators and dance practitioners explored viable ways to disseminate dance. Similarly, the use of audio shows the impact of multi-technology in dance education; as a stimulus for dance education, choreography and performance, multi-technology is evolving in the field of dance (Tomczak, 2001). In the last few years, there has been much research into the use of technology in dance performance and dance education. These studies have shown that the teaching methods used in dance have an essential impact. However, there is still an increasingly wide space to explore multimedia technology applied in dance teaching as the technology saw a blooming development.

\subsection{The Application of Video and Online classes in dance teaching}

Over the years, dancers and dance practitioners have widely used video and online dance courses to collaborate on transmission projects. Especially under the influence of covid-19, the gags of online resources, dance courses and dance cooperation projects have sprung up. Dance teachers use different media applications for communication and teaching. For instance, Zoom, Micro teams, Skype, and Tencent Meeting. In China, various media and websites provide people with resources to learn dance. Examples include Mu class, Netease cloud class and Dance China and so on. These accessible resources provide a convenient way for dance majored students and amateur dancers to improve dance knowledge and the opportunities to collaborate (Bannon, 2004).

Dance educators' research includes exploring how multimedia technology in the classroom can impact student learning. For example, due to advances in technology, dance is interwoven with technological elements in teaching, performance, and choreography. As a result of these technological advances, it is becoming increasingly important that dance students have and maintain the technological skills and advances currently used to create, produce and document creative and academic work. Similarly, an interactive artistic production process is involved in choreography through internet communication, which creates an inclusive learning environment. The incorporation of collaborative teaching and learning practices through a range of technological platforms enables students to hone their collaborative skills, and requires critical digital literacy in today's professional world. During the Covid-19 period, teaching practices included students using video portfolios of choreographed and edited dance images to teach dance. This process involves teaching innovation using computer-mediated resources (such as video editing, graphic design, and web development software). Students' creativity is stimulated by collaborating with artists and scholars in other disciplines to integrate technology and innovative methods - teaching process and performance (Tomczak, 2001).

\subsection{Audio Applied in dance teaching}

Audio is a coding technology that surrounds the sound in three dimensions, allowing the audience to experience various sound sensations through the different directions of the sound source, which creates a playback field. In addition to being fixed at the source, it is contextualized by the psychology of the audio equipment The sound is first sent directly to a specific location and then extended by reverberation so that the mix can be overlaid without destroying the previous sound, thus bringing out the surround effect. This creates stereo in a given environment by allowing sound to move back and forth. In dance performances, sound and audio are used to enhance the live soundtrack. Some of the more familiar ones are 3D surround sound, Sound Installation, and soundscape. The combination of music and multimedia technology is used on stage, and music and laser technology complement the dancers' performances.

With the artistic development of audio and soundtracks, it also reflected in dance teaching. For example, in Beijing 9 Contemporary Dance Company's classes, the technicians used a very advanced audio control technology to playback all the sounds and then processed them through multi-track audio playback to create a three-dimensional sound surround effect. The 
students recreate parts of the scenes with body movements in a stereo surround sound atmosphere. This immersive classroom atmosphere provides a safe and realistic environment in which students can relax. In addition, the audio plays a role in improvisation training (Leijen, 2009).

Similarly, the synthesis of human movement through learning technology is becoming an increasingly popular method in training instruction to alleviate the need for new data capture to produce animation (Ferreira, 2021). Dancers learn to move naturally from music. 2019 in China, Music-Driven Dance Generation uses a training model of dance movement synthesis with music/audio sequences coded to form a database of music and corresponding dance movements collected. Ferreira et al. (2021) devised a GCN model to generate dance with music. This method of training has been used to obtain more realistic movement metrics. The use of audio has a possible meaning for dance teaching, and it brings positive energy for dance teachers to collaborate with different art forms. To conclude this innovative improvement of dance teaching, audio has these benefits to dance education.

\section{CONCLUSION}

At present, the development of multimedia has been widely used in dance performance and dance teaching. In China, multimedia technology has involved different dance classes, and students can access the available resources. The results of this study show that the application potential of multimedia technology in the field of dance is increasing, including in dance performances, video and projection are used for the dance performance, virtual reality gives audiences more creative and immersive environments, and interactive installations provide possibilities for art Sexual expression and cooperation opportunities. For dance education, the use of video shuts down the relationship between dancers and international communication. Audio provides an innovative teaching method for improvisation. The use of multimedia technology may break some perception barriers. In particular, the dancers of the future may create a new social and cultural context.

\section{AUTHORS' CONTRIBUTIONS}

Yanling Sun conceptualised and experimented on the study and conducted the data analysis, and wrote the manuscript.

\section{ACKNOWLEDGMENTS}

I would like to take this opportunity to thank my family and friends for their encouragement and support during my research process.

\section{REFERENCES}

[1] Bannon, F. (2004). Towards creative practice in research in dance education. Research in dance education, 5(1), 25-43.

[2] Chan, J. C., Leung, H., Tang, J. K., \& Komura, T. (2010). A virtual reality dance training system using motion capture technology. IEEE transactions on learning technologies, 4(2), 187-195.

[3] Ferreira, J. P., Coutinho, T. M., Gomes, T. L., Neto, J. F., Azevedo, R., Martins, R., \& Nascimento, E. R. (2021). Learning to dance: A graph convolutional adversarial network to generate realistic dance motions from audio. Computers \& Graphics, 94, 1121.

[4] Heyang, T., \& Martin, R. (2020). A reimagined world: international tertiary dance education in light of COVID-19. Research in Dance Education, 1-15.

[5] Jola, C., \& Grosbras, M. H. (2013). In the here and now: Enhanced motor corticospinal excitability in novices when watching live compared to video recorded dance. Cognitive Neuroscience, 4(2), 9098.

[6] Kyan, M., Sun, G., Li, H., Zhong, L., Muneesawang, P., Dong, N., ... \& Guan, L. (2015). An approach to ballet dance training through $\mathrm{ms}$ kinect and visualization in a cave virtual reality environment. ACM Transactions on Intelligent Systems and Technology (TIST), 6(2), 1-37.

[7] Leijen, Ä. (2009, July). Acknowledging practice: The applications of streaming audio and video for tertiary music and dance education. In 2009 Ninth IEEE International Conference on Advanced Learning Technologies (pp. 101-103). IEEE.

[8] Leo, L. (2007). Corposcopio: an interactive installation performance in the intersection of ritual, dance and new technologies. Technoetic Arts, 5(2), 113-117.

[9] Parrish, M. (2007). Technology in dance education. In International handbook of research in arts education (pp. 1381-1397). Springer, Dordrecht.

[10] Skjulstad, S., Morrison, A., \& Aaberge, A. (2002). Researching performance, performing research: dance, multimedia and learning. Researching ICTs in context, 211-248.

[11] Tardieu, D., Siebert, X., Mazzarino, B., Chessini, R., Dubois, J., Dupont, S., ... \& Visentin, A. (2010). Browsing a dance video collection: dance analysis and interface design. Journal on Multimodal User Interfaces, 4(1), 37-46.

[12] Tomczak, K. (2011). Using interactive media in dance education. Journal of Dance Education, 11(4), 137-139. 